\title{
A Renewal of Astronomy Edcuation in Vietnam
}

\author{
Donat G. Wentzel \\ University of Maryland, College Park, Maryland, U.S.A. e-mail: \\ wentzel@astro.umd.edu
}

\begin{abstract}
Vietnam was scientifically completely isolated for almost 30 years. With French help, several lecture courses have introduced modern astrophysics to Vietnamese physicists, and four students are studying abroad. The IAU program "Teaching for Astronomy Development" (TAD) has concentrated on modernizing the on-going astronomy course for students in the third year of the pedagogical universities. Three oneto-two week "Teachers' Workshops" have served to introduce selected up-to-date astronomical topics and a few modern teaching methods. The TAD program has also provided appropriate journals, books, a PC and educational software. A new text, Astrophysics, in Vietnamese and English on facing pages and with color pictures - apparently a first for any textbook in Vietnam - will first be used starting in September 2000.

Future additional activities: collaboration to plan a new astronomy course in the twelfth grade of the natural science branch of the secondary schools; collaboration so that the 41-cm telescope and astronomers in Hanoi can produce some simple quality science; helping the only planetarium in Vietnam to acquire a wider range of offerings; helping to create a set of B.Sc.-level astrophysics courses for three universities; and supporting the Vietnamese Astronomical Society in effective public outreach.
\end{abstract}

Vietnam was scientifically isolated for thirty years. Although astronomy has been a required subject for physics students in ten pedagogical universities for many years, the astronomy textbook used until this year is far out of date, and it has no photographs. Astronomy almost disappeared during thirty years of war. In general, science education is by lecture that is to be memorized (as is the case in many places); there are practically no hands-on laboratory experiments for students; and, during the thirty years of war, an entire generation of scientists has been trained without participating in the process of science, in exploring nature, in measuring things, in interpreting data. Therefore, the few senior Vietnamese astronomers have sought to re-introduce astronomy as a frontier science. With French help, several lecture courses have introduced modern astrophysics to Vietnamese physicists; and the first of several students studying in France has received a Ph.D. and will soon return to a position at the National University of Hanoi. 
The IAU program "Teaching for Astronomy Development" (TAD) is designed to help scientifically developing countries that express an interest in enhancing astronomy in the country over the long term.

In Vietnam, the main task for TAD has been to train the teachers of the ongoing astronomy course in the pedagogical universities. Three 1-2-week "Teachers' Workshops" - one of which included nationally selected physics students were organized with international faculty (N. Q. Rieu, J. C. White II, D. G. Wentzel). The workshops gradually introduced up-to-date astronomical topics and reviewed the associated physics. We used a small part of Hands-onAstrophysics from AAVSO. The teachers have been delighted to learn more interactive ways of teaching than writing on a blackboard, and they practice at home what they learn at the workshops. Saunders College Publishing provided up-to-date textbooks, in English and containing many color photos. The TAD program has also provided appropriate journals, books, a PC, and educational software. We have written a new text, Astrophysics, printed in Vietnamese and English on facing pages. The IAU financial support made possible that the new text contains color pictures, which apparently is a first for any science textbook in Vietnam.

It is now time to expand the TAD activities. First, we plan to provide a support system for the university teachers in the semester when they first use the new text. Because most teachers do not yet have e-mail available, they will depend heavily on telephone to the three main universities which do have e-mail. Second, once the new course is established, we plan to help the Vietnamese teachers and astronomers to broaden the base of support for astronomy by sponsoring two more workshops. Third, we shall advise on a set of astrophysics courses that will be started in three universities so that a few students can study astronomy at a more advanced level. Fourth, we expect to support the Vietnamese Astronomical Society in seeking effective interdisciplinary public outreach.

The Vietnamese astronomers face a very difficult educational challenge. The ongoing astronomy course is given in pedagogical universities, but it focuses on the science of astronomy. It is not pedagogically oriented. Nevertheless, the university physics students taking this astronomy course will themselves teach astronomy courses in the schools. A twelfth-grade course on the solar system has been approved for the natural-sciences branch of secondary schools. Ideally, we would like the new course to become a seed for more effective science education nationwide. But the IAU cannot support the direct training of school teachers. That would overwhelm our resources. The Vietnamese will have to provide the teacher training. We can only help in the planning of the course and the textbook, we can only suggest that the new course include some learner activities and address frequent misconceptions, and so the educational seed we plant may be very small indeed.

There is also an observational challenge. The Pedagogical University of Hanoi received, from the Sumimoto Science Foundation of Japan, a 40-cm Meade Schmidt-Cassegrain telescope which is large enough that students, in principle, can experience the excitement of scientific inquiry by participating in observational research projects. However, the telescope has been used only for astrophotography. There is a CCD and a new computer, but the telescope is 
poorly mounted and there is not yet a capability to use the CCD and to analyze the data. There is no experience in what constitutes quality data. As a first step toward improving the observational capabilities, TAD sent a staff member to attend the UN/ESA workshop in Toulouse and to meet with experienced observers in Toulouse who use small telescopes.

The first planetarium in Vietnam has opened in Vinh City, with a GOTO projector received as a Cultural Grant-in-Aid from Japan. The audiences are both school classes and the public. The first show begins with local interests and then expands to survey all of astronomy. Two new shows (one donated) from Davis Planetarium, Baltimore, U.S.A. await translation and some cultural adjustment before they can be shown in Vietnam. A second planetarium is to be built in Hanoi, with support from France. We would like to see the planetaria used with the schools in a western-style class-participation mode, but this would require considerable adaptation of the local teachers and teaching system, far beyond the capacity of the current planetarium staff.

Acknowledgments. I want to thank my two long-term collaborators and advisors in this project, Professor Nguyen Quang Rieu from Paris Observatory and Professor Nguyen Dinh Huan, who is Rector of Vinh University and VicePresident of the Vietnam Astronomical Society. I thank James C. White II, Astronomical Society of the Pacific, for his advice and participation. Part of the TAD program was supported by grants to the IAU from ICSU.

\section{Discussion}

Rieu commented that, in addition to the optical telescope, there is a radio interferometer built at the Radio Astronomy Centre at Nançay (Paris Observatory) and offered to the University of Hanoi on the occasion of the solar eclipse of October, 1995, (Editor's note; see Rieu's paper, pp. 255-265.) He also said that part of the problem with the 40-cm telescope was vibration of the floor on which it is installed. Until that is solved, the telescope will not provide good images. Kozai emphasized that he himself took the telescope and CCD camera to Hanoi and assured himself that they worked well. (Editor's note: see also Kitamura's poster paper, p. 312-3.) Boice asked about science education in the primary and secondary schools of Viet Nam. Are students entering the undergraduate astronomy course well-enough prepared in mathematics and science to be successful? Wentzel replied that he did not know enough about Vietnamese schools to give a complete answer. The undergraduates appeared to be familiar with the appropriate principles and formulae but to lack the ability to think critically. In reply to a query from Celebre, Wentzel said that countries wishing to be consider4ed for a TAD program should, in the first instance, approach Batten. 